Earth and Environment | Cyrille Rigolot

\section{Quantum theory for sustainability transformations}

\begin{tabular}{|c|c|}
\hline $\begin{array}{l}\text { Agriculture significantly } \\
\text { contributes to environmental } \\
\text { issues and requires deep } \\
\text { and urgent transformations } \\
\text { in order to be sustainable. } \\
\text { Agroecological transition is } \\
\text { not only technical but involves } \\
\text { the evolution of farmers' ways } \\
\text { of seeing and interpreting the } \\
\text { world. Dr Cyrille Rigolot at } \\
\text { the French National Research } \\
\text { Institute for Agriculture, Food } \\
\text { and the Environment INRAE), } \\
\text { explores the potential of } \\
\text { quantum theory as a source } \\
\text { of insight to foster deep } \\
\text { sustainability transformations. } \\
\text { His strategy is being put to } \\
\text { the test through participatory } \\
\text { projects with farmers, farm } \\
\text { schools and extension services. }\end{array}$ & 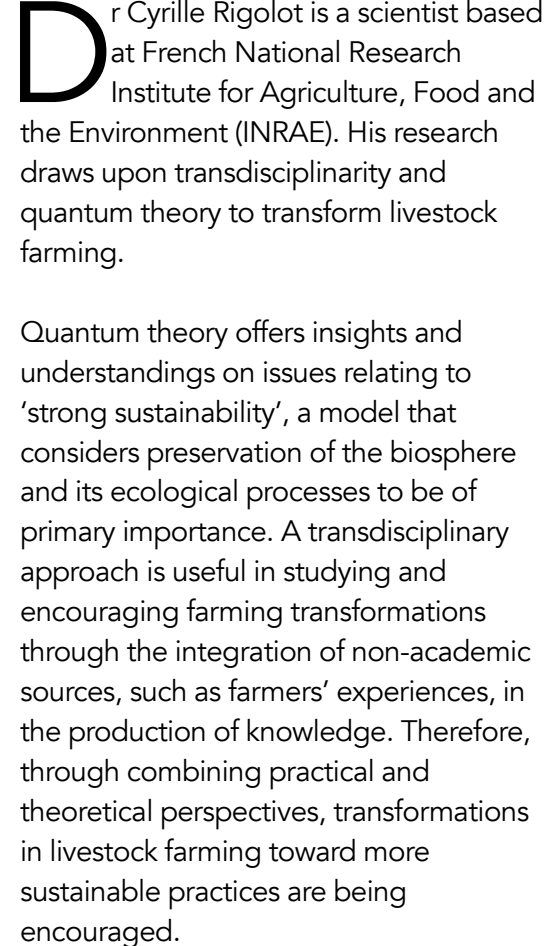 \\
\hline
\end{tabular}

\section{QUANTUM THEORY} AND FARMING
Currently, the livestock sector uses $30 \%$ of the Earth's land, $32 \%$ of its water, and contributes
$18 \%$ of greenhouse gas emissions. This
trend contributes to the present era
being defined as the Anthropocen epoch, due to the impact humans are having
on the Earth's on the Earth's
ecosystems. These global trends require
glosysems. These transformations in farming practices, and also social change in the values farmers hold about the land and nature. Rigolot and colleagues are working with farmers they follow The research is informed by the surprising premise that quantum theory provides a source of insights when working alongside stakeholders, such as farmers in problem-solving projects.

To encourage strong sustainability, transformations in agricultural practices and a simultaneous shift in worldviews (the values and meanings a person gives to the world) are necessary. Even though they may farm in the same area or region farmers can hold differing views on sustainability, and this factor influences agroecological transformations. Whereas modem farming practices see through te hnical and chirnme means, in agroecology farmers work with the land to improve soil quality, animal wellbeing, and biodiversity. The transdisciplinarity approach is a promising trend, as it seeks to understand not just the management of farmed land, but the complex web of interactions between farmers and their worldviews, the land, the livestock, and management practices.

\section{TRANSDISCIPLINARITY:}

THEORETICAL AND PRACTICAL Two modes of transdisciplinary research have been identified: in Mode 1 , a theoretical view is taken to gain a detached, generalised understanding of the world, in Mode 2, an involved, hands-

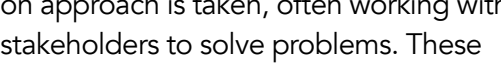

two modes have mainly developed independently, with Mode 1 lacking 2 is too superficial given the sustainability challenges ahead: taking either stance on its own has the potential to exclude the other. Therefore, the quantum concept of complementarity may help to address the gap between these modes that appear to take very different paths - the former mode being theory-based, and the latter being practical. This quantum conceptualsation allows a co-existence of paths, such that an individual farmer may make choices according to context and current requirements, rather than

Sustainability transformations, where a farmer shifts from one worldview meaning that there is no straightfially, conversion route for farmers Quantum approaches help to conceptualise this non-linearity, implying that there are multiple narratives for change. Farmers' preferences are often not well defined, but instead they exist in a state of possibilities, where the Self, until the point of action, is a mix of potential actions and options. The Self, or individual, is not entirely controlled by external forces, such as the political sphere, nor strictly driven by personal, internalised forces, rather, they are shaped by external and internal factors, recognition of these factors can and who is lisesed to. For exacted indigenous knowledge or the use of biodynamic farming methods have so far been underexplored, yet through a quantum lens there may be insights from these practitioners that are releva for sustainability and transformations.

\section{QUANTUM CONSCIOUSNESS?} Fostering transformations in stakeholders' perspectives benefits from consideration of three spheres of transformation understood as the Political, the Personal and the Practical. Whilst it has been suggested that change must initially occur in the political sphere as part of sequential ransformation, the persona sphere may be more significant than at this level then scaling-out to effect

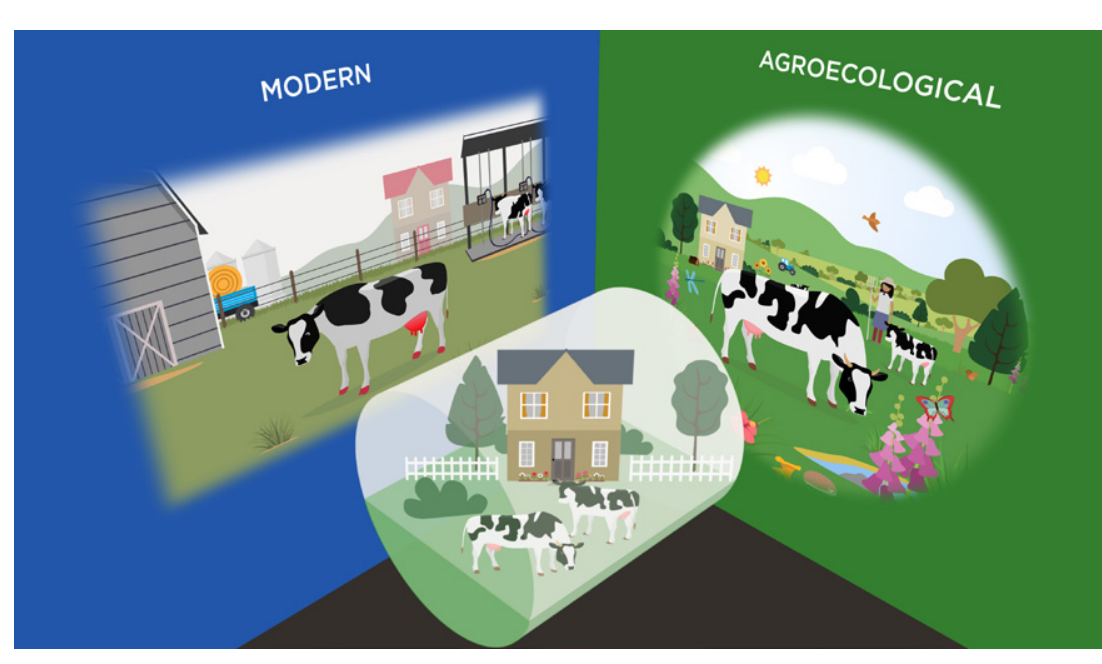

The "cylinder metaphor" illustrates the quantum principle of complementarity: a cylinder looks like
a circle from one perspective and a rectangle from another perspective. To some extent, farmers' in such a way that prevents getting the full picture of the object considered (the farm)

Currently, the livestock sector uses $30 \%$ of the Earth's land, $32 \%$ of its water, and contributes $18 \%$ of greenhouse gas emissions.

transformations in the political sphere. The work of Karen O'Brien (2015) can be used to illustrate this persona, subjective transformation. She has proposed that somewhat like a ripple
effect, small individual actions can have a global influence. Again, quantum

theory helps to understand the subtlety and complexity of how transformation happen. 'Quantum consciousness'

has been proposed as having something new to offer to the social sciences, with regard to undectianding human

of social issues, social change, and the subjectivity behind them. This idea is currently quite speculative, but taking it seriously reminds us that knowledge ground to stand on.

This quantum approach conceives of the entangled, joined-together, and interacting ways in which spheres (a) for reseals. This also has mplcat for research methodologies that seek

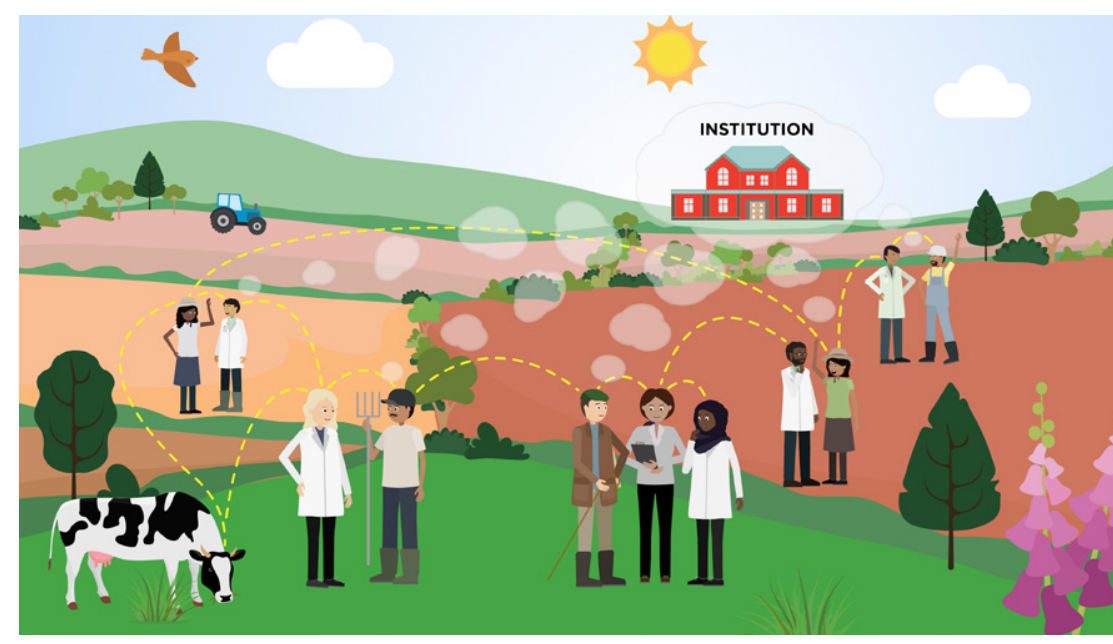

Following a quantum social approach, individuals are seen as "entangled" rather than fully
separable entities. Social structures (i.e. institutions) are seen as both external and interna 


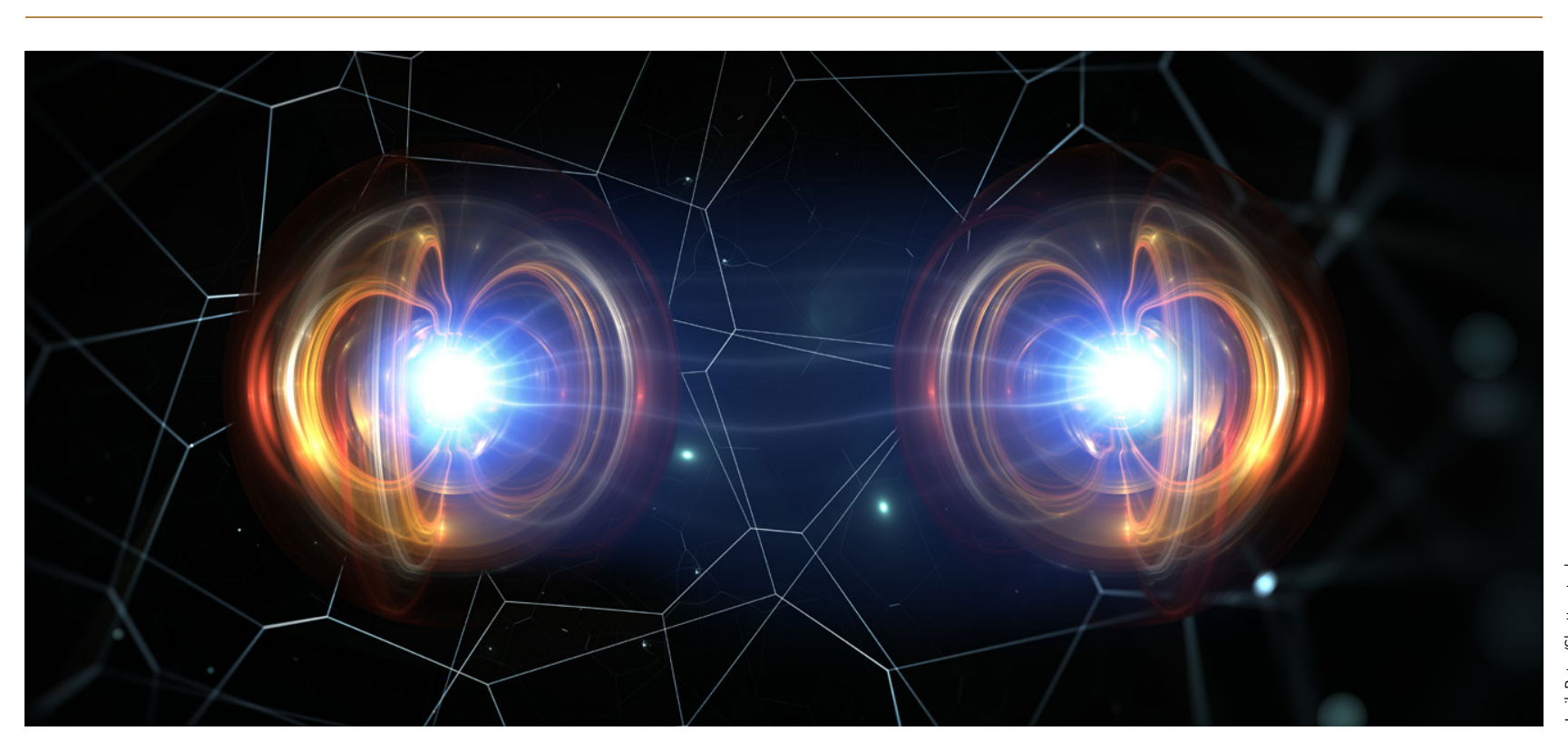

and transformations in their livestock physics regards and bellefs. Classical with a limited or nop-existent capaity for freewill or subjectivity a somewh restrictive perspective, whereas a quantum approach recognises the significance of subjectivity. The quantum consciousness hypothesis is supportive of this view: it explains the Self as only becoming determinate upon acting, as up until that point, multiple possibilities and routes exist. This attitude can help experts to shape the advice they give to farmers, working alongside and encouraging them to take steps to transform their farming methods in a dynamic way that permits for their ow agency and actions.

FARMER'S WORLDVIEWS Rigolot and colleagues (2018) conducted comprehensive interviews

Insights from quantum theory convey a radical meaning, which might be essential to foster deep sustainability transformations.

with French dairy farmers to explore farming habits being carried forward their worldviews, and four different generation to generation. Within these types emerged. The Modern, which four different types, farmers sometimes aims to maximise and control pastures held coexisting worldviews, for example, and animal production, with a focus on efficient production and economic return; the Ecological Intensive, which seeks good productivity without controlling the environment throug working with local soil characteristics. The Holist approach regards farming as a part of nature, whose protection distinguishes between a naturat and distinguishes between a natural and

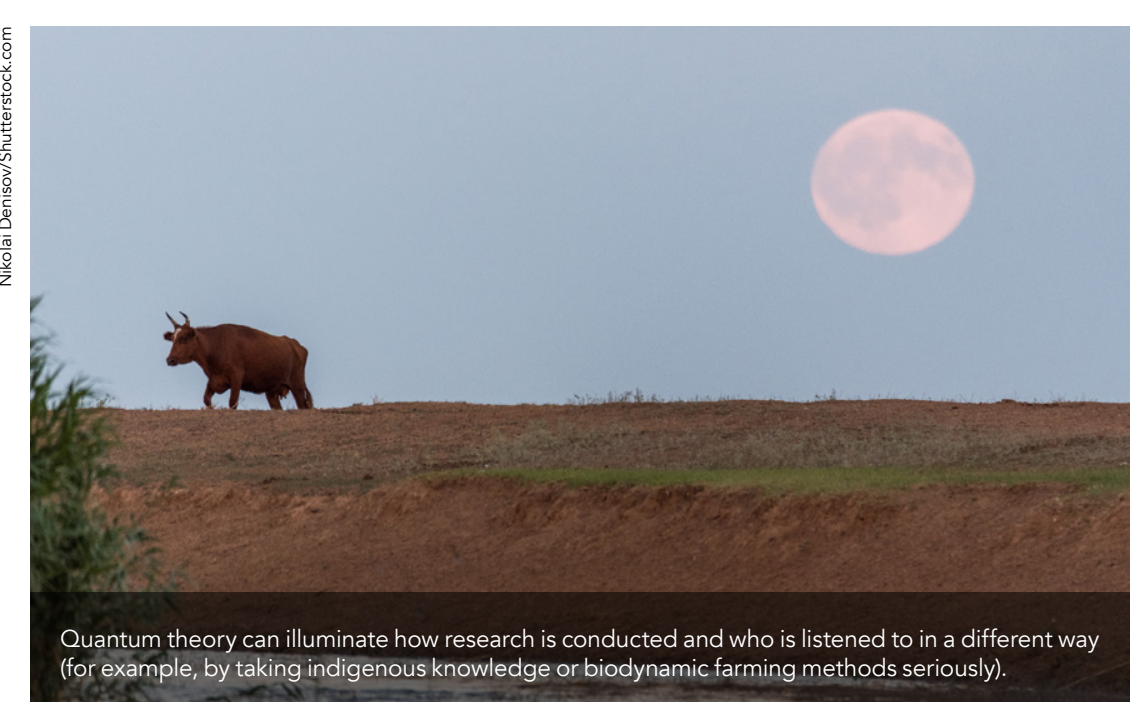

using both traditional and modern

farming techniques.

These results offer useful insights for technical experts who advise farmers these experts have a key role to play farmers value their guidance. Farmers' practices that accompany those views are instrumental in shaping sustainabilit

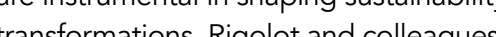
research indicates that supplying containing ideas on worldviews could help them adapt their advice to each farmer. This is supported by the findings from workshops with farmers, which revealed that their perspectives can and do alter, demonstrating that transformations are possible at the personal level. Despite quantum theory being connected with laboratory-based and seemingly impractical theorising, it sustainable transformations, with farmers, working together to develop sustaina
transformations in farming practices. in agroecological transformations as experts with simple information sheets has the potential to explore and promote echnical experts, and academic advisors

\section{Behind the Research}

Cyrille Rigolot

E: cyrille.rigolo@@inra.fr $\quad$ T: $+33(0) 473624240$

W: hyttps://www.researchgate.net/profile/Cyrille_Rigolot

Research Objectives

Cyrille Rigolot's research aims to find sustainable pathways for agriculture where people, animals and nature can thrive.

Detail

Cyrille Rigolot

INRAE UMR Territoire

Shampanelle

France

Bio

Cyrille Rigolot is a scientist at INRAE, and deputy director of the joint research unit "Territoires". His research aims to understand and foster deep transformations of livestock interested in transdisciplinary approa. Hes combining

\section{References}

Rigolot, C. (2019) Quantum theory as a source of insights to close the gap between Mode 1 and Mode 2 way forward. Sustainability Science. doi: 10.1007/s11625019-00730-8

Rigolot, C. (2019) Magic and Muck: On Chicken and Egg Problems When Framing Organic Conversions as Sphere. Society and Natural Resources. https://doi.org/1 0.1080/08941920.2019.1673523

Rigolot, C. (2018) Sustainability transformations as shifts in worldviews. a dynamic view of complementarity

Cayre, P., Michaud, A., Theau JP, \& Rigolot C. (2018) The Coexistence of Multiple Worldviews in Livestock Farming Drives Agroecological Transition: A Case Study in French Protected Designation of Origin (PDO) Cheese https://doi.org/10.3390/su10041097

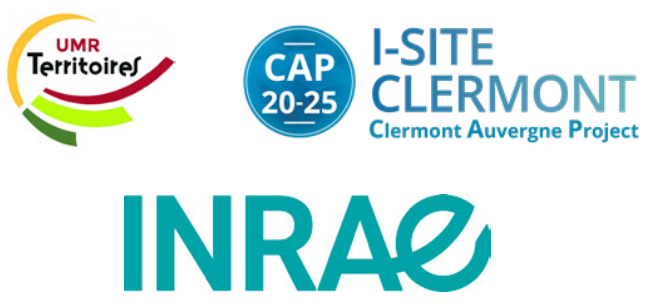

natural and social sciences together with stakeholders' knowledge outside the academia.

Funding

French government IDEX-ISITE initiative 16-IDEX-0001 (CAP 20-25)

\section{Collaborator}

- Patrice Cayre, French Agriculture Ministry, Research - Pat Teaching General Division (DGER)

University of Technology

\section{Personal Response}

Are dairy farming techniques becoming more sustainable due to your research findings and your proposed approach?

II My approach aims at activating what Donnella Meadows calls "deep leverage points", the level of worldviews and paradigms. These are very difficult to change, but a small change there can bring the
radical system shifts that are required. This approach is complementary to incremental technical changes, which are easier but more superficial. In our participatory project, our transdisciplinary approach really helps some farmers engaged in difficult to achieve agroecological transitions. Some of these farmers are managing implications for the education of the next generation of farmers. My hope is that the quantum approach could contribute to upscale radical sustainable change beyond this project. This is possible but uncertain: somehow this
is a risk.

Do you foresee other environmental sectors also for example forestry, fishing, crop farming? II Absolutely. For example, quantum-inspired
techniques such as "Q methodology" have been used for forestry, fishing and several other sectors. There are also promising quantum applications in other research In fact, quantum approches could be used potentilly in every human-related domain: this is more about people than about any particular sector. 